\title{
Mujeres, inmigrantes y jóvenes: formas de acceso informal al hábitat en la ciudad
}

\author{
Mulheres, imigrantes e jovens: meios informais de acesso à habitação na \\ cidade
}

Women, immigrants and youth: forms of informal access to habitat in the city

María Carla Rodríguez ${ }^{[a, b]}$, María Florencia Rodríguez ${ }^{[a, b]}$, María Cecilia Zapata ${ }^{[a, b]}$

[a] Consejo Nacional de Investigaciones Científicas y Técnicas (CONICET), Ciudad Autónoma de Buenos Aires, Argentina
[b] Universidad de Buenos Aires, Instituto de Investigaciones Gino Germani, Ciudad Autónoma de Buenos Aires, Argentina

\section{Resumen}

En la Ciudad Autónoma de Buenos Aires (CABA-Argentina) la población en villas creció significativamente, durante el período intercensal 2001-2010, en un 52,3\%, según el Censo Nacional de Población, Hogares y Viviendas 2010. Parte de este proceso se manifestó a través de la proliferación de un mercado informal de piezas en alquiler donde mujeres, inmigrantes y jóvenes precarizados resuelven el acceso al "techo", ante la carencia de opciones habitacionales por la vía del mercado formal. En base a la realización de una encuesta en 5 villas de la ciudad y de entrevistas en profundidad a informantes clave (funcionarios públicos, referentes barriales y académicos), este artículo aborda, en perspectiva sociológica, el perfil socioeconómico de los inquilinos, las condiciones de habitabilidad y las características que asume la dinámica de este mercado informal. La hipótesis que guía este trabajo es que los perfiles sociales más vulnerados y excluidos del acceso al hábitat en la ciudad —que conjugan posición de clase, género, dinámicas migratorias e intergeneracionales- son los que configuran la demanda efectiva del mercado informal de alquiler de piezas en villas. A su vez, esto ha sido posibilitado por el desarrollo de políticas urbanas neoliberales que favorecieron la desregulación del mercado formal de suelo y alentaron el informal provocando, en este último, mayor segregación socioespacial a escala intrabarrial.

Palabras clave: Sociología urbana. Mercado informal. Inquilinos. Villas. Ciudad Autónoma de Buenos Aires.

\section{Resumo}

Na Cidade Autônoma de Buenos Aires (CABA-Argentina), a população das favelas cresceu significativamente $(52,3 \%)$ durante o período do censo demográfico feito entre 2001-2010, de acordo com o Censo Nacional de População, Moradia e Habitação 2010. Parte desse processo foi manifestado pela proliferação de um mercado informal de quartos para alugar, por meio do qual mulheres, imigrantes e jovens em situação precária resolveram o acesso ao "teto" em razão da falta de opções habitacionais pelo mercado formal. Baseado em uma pesquisa em cinco favelas na cidade e em entrevistas em profundidade com informantes-chave (funcionários do governo, acadêmicos e representantes de bairro), este artigo se focaliza em atender, na perspectiva sociológica, ao

MCR est doctora en Ciencias Sociales de la Universidad de Buenos Aires, e-mail: trebol1968@gmail.com MFR est doctora en Ciencias Sociales de la Universidad de Buenos Aires, e-mail: mafloro@gmail.com MCZ est doctora en Ciencias Sociales de la Universidad de Buenos Aires, e-mail: ceciliazapata@gmail.com 
perfil socioeconômico do arrendatário, às condições de permanência de quartos alugados e às características assumidas pela dinâmica comercial dos envolvidos nesse mercado informal. A hipótese que guia este trabalho é que os perfis sociais mais vulneráveis e excluídos do acesso à habitação na cidade - que conjugam posição de classe, gênero, dinâmicas migratórias e intergeneracionais - são os que configuram a demanda efetiva de um mercado informal de aluguar quartos em favelas. Isso foi possível pelo desenvolvimento de políticas urbanas neoliberais que favoreceram a desregulamentação do mercado formal da terra e encorajaram o informal, causando, neste último, maior segregação socioespacial em escala intrabairro.

Palavras-chave: Sociologia urbana. Mercado informal. Inquilinos. Favelas. Cidade de Buenos Aires.

\section{Abstract}

The urban settlements population in the Autonomous City of Buenos Aires (Argentina) grew a significant 52.3\%, between 2001-2010, according to the National Population, Household and Housing Census 2010. Part of this process was manifested by the proliferation of an informal market of rental rooms offered for women, immigrants and young people in precarious situation, which provides access to a home in the lack of housing options via the formal market. Based on a survey of 5 slums and in-depth interviews with key informants (public officials, neighborhood referrals and academics), this article is a sociological approach to understand the socioeconomic profile of the tenants, the living conditions of the rented spaces and the characteristics assumed by the commercial dynamics of those involved in this informal market. We hypothesize that most of the effective demand for informal rental market in slums comes from those with most vulnerable profiles and without access to the habitat in the city - which combine class position, gender, migratory and intergenerational dynamics. This is a consequence of neoliberal urban policies that favored the deregulation of the formal land market and encouraged the informal, causing, in the latter, greater socio-spatial segregation on an intra-neighborhood scale.

Keywords: Urban sociology. Informal market. Tenants. Urban settlements. Buenos Aires city.

\section{Introducción}

El último Censo Nacional de Población, Hogares y Viviendas (INDEC, 2010) registró, para el período 2001-2010, un total de 115.898 hogares nuevos que alquilan en la Ciudad Autónoma de Buenos Aires (CABA). Hacia el 2001, los inquilinos alcanzaban un $22 \%$ (227.545 hogares), aumentando a un 30\% (343.443 hogares) al año 2010. Si bien, desde mediados del siglo XX, los propietarios de la vivienda y el terreno fueron mayoría frente a los inquilinos, a partir del último período intercensal se observa una tendencia a la reversión en ese patrón histórico del régimen de tenencia de la ciudad.

En ese contexto, el proceso de expansión del mercado de alquiler en villas, registra dos factores que presionaron estructuralmente (Bourdieu, 1997) a su surgimiento, consolidación y proliferación. Uno es el recrudecimiento, impulsado por una fuerte especulación inmobiliaria, de las condiciones de acceso a los contratos formales de locación ${ }^{1}$ junto con el alza sostenida de los precios de la vivienda en venta y en alquiler ${ }^{2,3}$. El otro factor es el deterioro progresivo de la capacidad adquisitiva de los ingresos de los

${ }^{1}$ Esto equivale al costo de 1 mes de alquiler por adelantado, más 2 o 3 de comisiones a inmobiliaria y gastos administrativos, más 1 o 2 de depósito, y garantía de propiedad de familiar directo en capital. Desde 2016, tras un fallo judicial, en concepto de comisiones y gasto administrativos no puede cobrarse más del 4,15\% del total del valor del contrato.

${ }^{2}$ Entre 2002 y 2014 el alza del precio del $\mathrm{m}^{2}$ para la venta representó un promedio de 359,5\%. En el alquiler, en enero 2014 el valor promedio de un departamento usado de 3 ambientes fue de U\$S949,3 (según cotización oficial promedio de enero 2014: $1 \mathrm{U} \$ \mathrm{~S}=\$ 7.09$ ). Al año anterior (enero 2013) la suba interanual representó el 35,1\%; y en relación al mismo período de 2009 el incremento representó el 63,9\% (CEyS, 2015).

${ }^{3}$ Adicionalmente se ofertaron distintas estrategias de acceso a la vivienda mediante la compra como créditos hipotecarios y garantías de bancarías para acceder al alquiler, pero todas 
trabajadores ${ }^{4}$ que, en promedio, destinan entre un tercio y el $50 \%$ del ingreso total familiar en alquiler 5 .

De acuerdo con los datos censales (INDEC, 2010), la población villera creció en un 52,3\% durante el período 2001-2010, que se evidenció en un aumento de 107.422 a 163.587 habitantes $^{6}$ (ver Mapa 1). Este crecimiento fue acompañado de un proceso de densificación vertical, a partir de la proliferación de un mercado de habitaciones/piezas ofrecidas en alquiler por agentes de diferentes características.

El presente artículo tiene por objetivo abordar las características que asume el mercado de alquiler informal en las villas de la ciudad, tomando en cuenta el perfil socioeconómico de los inquilinos, las condiciones de habitabilidad de las piezas alquiladas y las características que asume la dinámica mercantil de quienes participan de este mercado informal. A partir de datos de fuente primaria, obtenidos de una encuesta de 304 casos y 12 entrevistas en profundidad, se procedió a realizar un relevamiento en las villas 31 y 31 bis, 3, 21-24, 20 y Rodrigo Bueno (ver Mapa 2), localizadas en las comunas 8, 4 y 1 de la CABA, donde se concentra la mayor cantidad de población en villas (ver Mapa 3).

La hipótesis que guía este trabajo es que los perfiles sociales más vulnerados y excluidos del acceso al hábitat en la ciudad —que conjugan posición de clase, género, dinámicas migratorias e intergeneracionales- son los que configuran la demanda efectiva del mercado

fracasaron por las exigentes condiciones de ingreso a los programas. Para más información ver Ceys (2015).

${ }^{4}$ Según la Encuesta Anual de Hogares 2012, el 6,2\% de los trabajadores era desocupado, el 8,5\% subocupado y el 26,7\% desempeñaba su actividad de manera informal (CEyS, 2013). En el año 2016, la misma encuesta data que el 8\% de los trabajadores estaba desocupado, el 9,4\% subocupado y el $26 \%$ trabaja de manera informal.

${ }^{5}$ Sumado a la condición de precariedad relatada en la nota anterior, el Ingreso Total Familiar de un trabajador para el año 2012 fue de U\$S1.698 (según cotización oficial promedio de diciembre 2012: $1 \mathrm{U} \$ S=\$ 4,88$ ) y en 2011 el $23,3 \%$ de los hogares tenía ingresos menores que los necesarios para acceder a la canasta total. Escenario que dificulta fuertemente la posibilidad de acceso a la vivienda formal (CEyS, 2013).

${ }^{6}$ Referentes de villas y organizaciones territoriales aseguran sub-registros en los relevamientos censales en torno al crecimiento, expansión y densificación de las villas, en tanto muchos dueños y/o encargado de inquilinatos impiden el acceso a los censistas. informal de alquiler de piezas en villas. Esto fue posibilitado por el desarrollo de políticas urbanas neoliberales que favorecieron las desregulaciones del mercado de suelo formal y alentaron el informal provocando, en este último, mayor segregación socio-espacial a escala intra-barrial.

\section{Lógicas de producción y apropiación en la ciudad capitalista}

Con la crisis del fordismo urbano y el debilitamiento del Estado de Bienestar, el "retorno del mercado" funcionó como elemento determinante en el reordenamiento espacial y en la producción de la ciudad neoliberal (Abramo, 2012). La injerencia del Estado en materia de planificación urbana estuvo dirigida a estimular la expansión de los negocios urbanos de manera subsidiaria a la lógica mercantil (Harvey, 2007; Theodore et al., 2009). En un contexto de mercantilización expandida de bienes y servicios y procesos globales de "acumulación por desposesión" (Harvey, 2010), las dinámicas de producción de ciudad también estuvieron signadas por la propia necesidad de habitación de sus pobladores.

Desde inicios del siglo XX, trabajadores pobres e informales desplegaron, a través de acciones individuales y colectivas, diversas estrategias de acceso al hábitat, centralmente, mediante procesos de ocupación del suelo urbano y autoconstrucción, que contribuyeron, a través del tiempo, a la consolidación de villas y asentamientos. Abramo $(2003,2012)$ reconoce en las últimas décadas una variante de producción de la ciudad popular, que articula la producción "mercantil" de la ciudad con la de la "necesidad", y se manifiesta socialmente bajo la forma de "mercado informal de suelo" (Abramo, 2012, p. 36).

La definición de informal no supone adherir a un dualismo sobre la existencia de un mercado formal versus otro informal con lógicas independientes, sino más bien reconocer la existencia de acoplamientos e interrelaciones que dan cuenta de distintas formas en las que se resuelve la relación capital/trabajo consecuencia a escala global de la reestructuración del sistema capitalista (Portes, 1999; Carpio \& Novacovsky, 1999) - en donde amplios sectores de la población no lograron un efectivo proceso de integración social. 


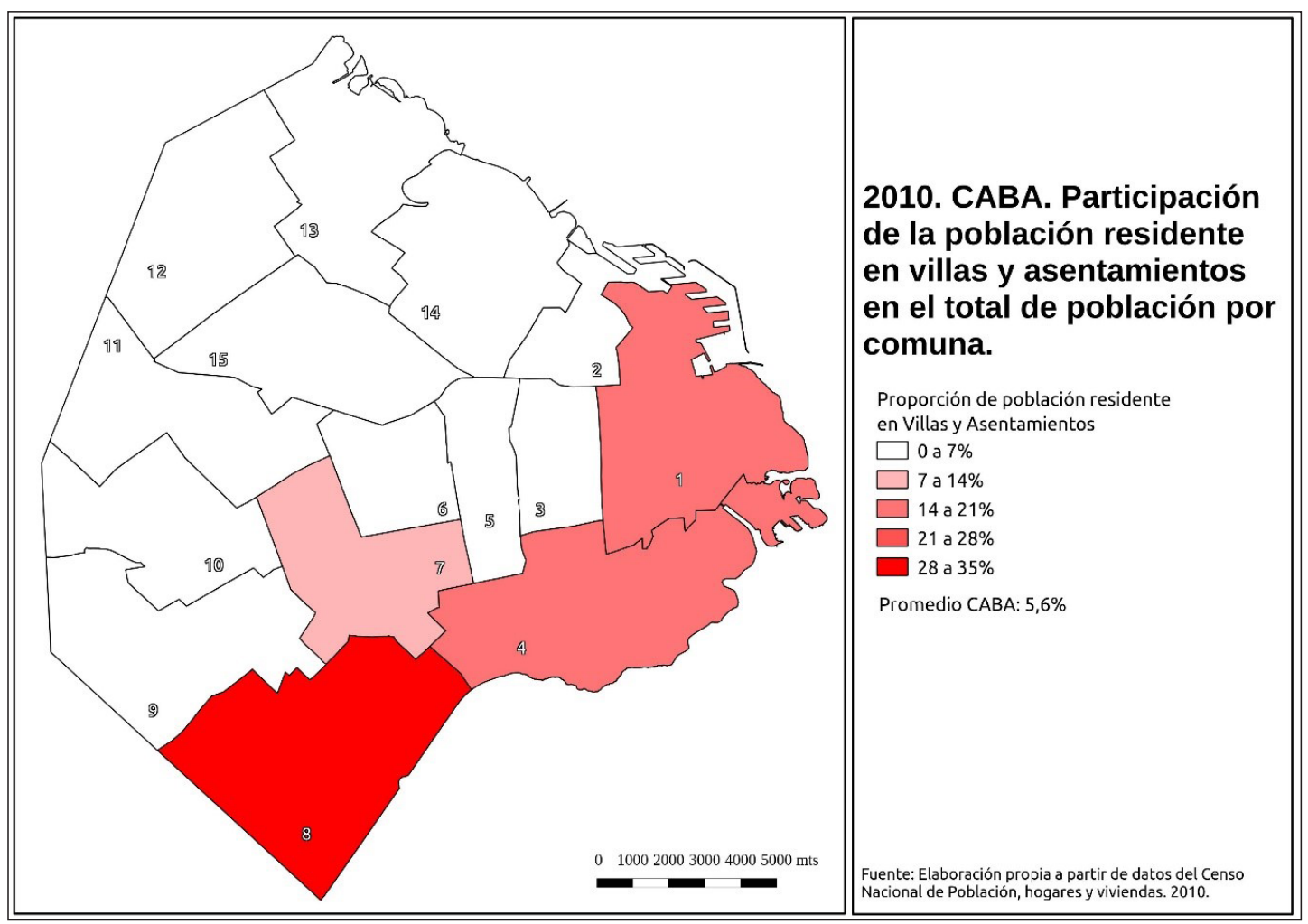

Mapa 1 - Proporción de población en villas y asentamientos en el total de la población por comuna. CABA, Argentina Fuente: CEyS (2013).

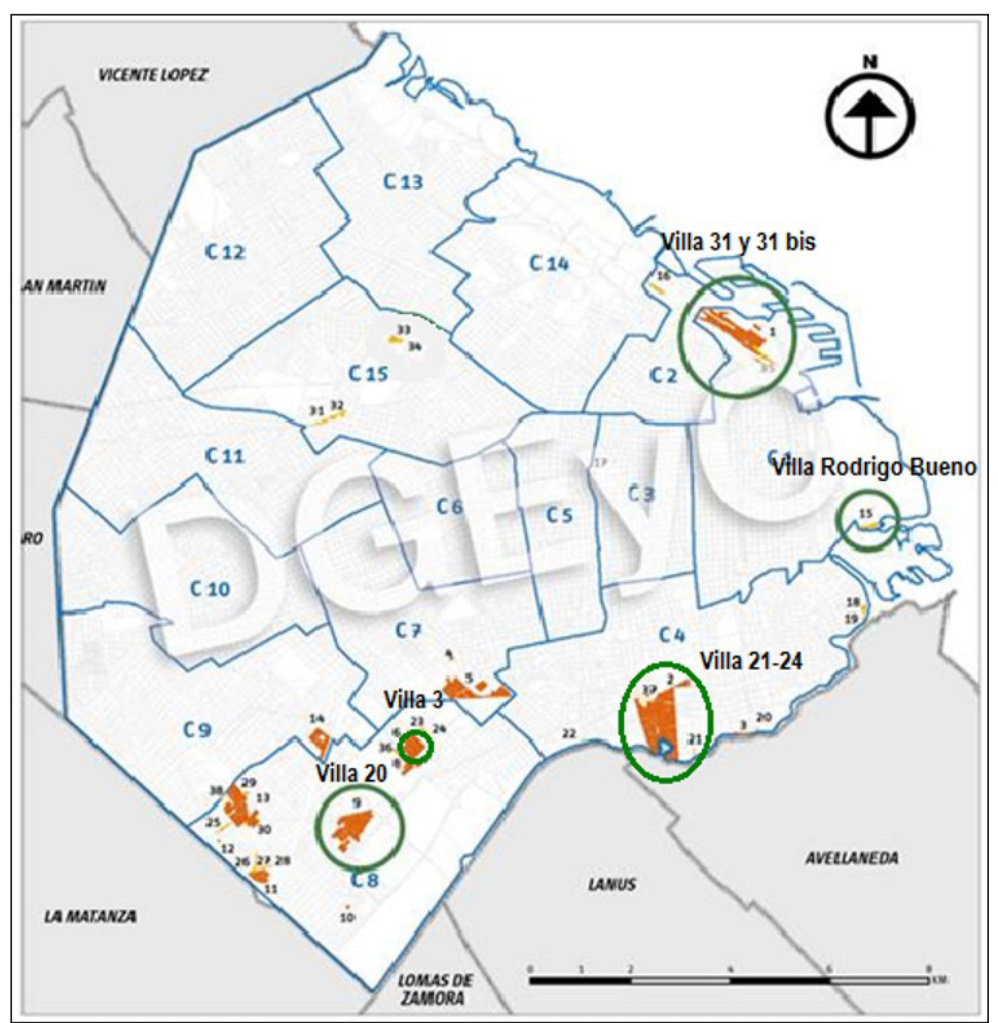

Mapa 2 - Villas analizadas: Villa $31-31$ bis, 3, 21-24, 20 y Rodrigo Bueno. CABA, Argentina Fuente: Elaboración propia. 


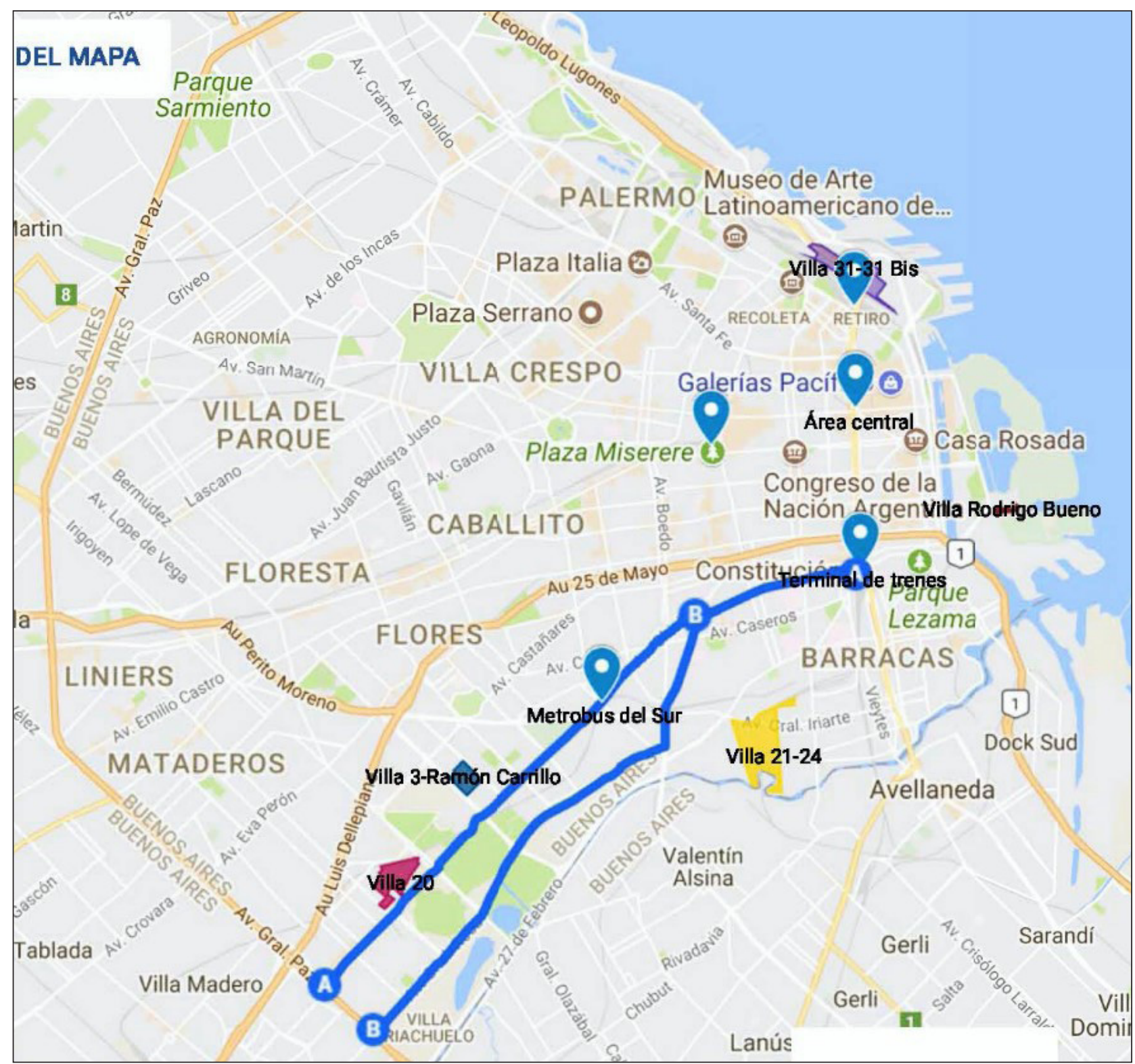

Mapa 3 - Localización y componentes de centralidad de las villas analizadas. CABA, Argentina Fuente: Elaboración propia en base a Google Maps.

\section{Mercado formal e informal del suelo: expresiones de una sola dinámica de la ciudad capitalista}

En términos generales, el proceso de valorización del suelo de la ciudad formal y el alza de los precios de los inmuebles - junto con los excesivos requisitos para calificar como locatario ante la falta de regulación de la dinámica del mercado inmobiliario - , contribuyeron a impulsar un marcado proceso de inquilinización. Esto se vio expresado en la proliferación de inquilinatos, hoteles-pensión, casas tomadas en la ciudad formal, así como también en inquilinatos y habitaciones ofrecidas en alquiler en las villas de la ciudad. En particular, en los últimos años, creció significativamente el mercado informal "secundario" dentro de las distintas formas de ocupaciones directas; debido a que en muchas ciudades no es posible la ocupación de más suelo, debido a que ya no existe. Varias investigaciones (Cravino, 2006; Abramo, 2003) señalan que los asentamientos informales se densifican y aparece el mercado informal tanto de compra-venta de inmuebles 
como de alquiler, (en villa, favelas, callampas, entre otros), ante la falta de vivienda.

En los casos abordados por esta investigación, este proceso se desarrolló sobre suelo de propiedad pública, por lo cual la expansión del entramado de actores y arreglos que configuran este mercado de alquileres informal, introduce mayor heterogeneidad y complejidad, profundizando la progresiva apropiación y privatización del suelo en condiciones altamente desreguladas, que fueron favorecidas por la omisión del Estado y sus políticas públicas de acceso al suelo urbano.

Diversos autores hacen referencia a los aspectos diferenciales entre el mercado formal e informal. El mercado informal remite, según Portes (1999), a una relación de externalidad y/o conflicto con las normas e instituciones del Estado/mercado formal; que varía según las relaciones históricas entre el propio Estado y la sociedad y como esta relación se expresa en la conformación de un determinado tipo de mercado. Trata de prácticas económicas concretas que eluden o violan las regulaciones estatales, pero el carácter de esas infracciones se rige por la relación contextualizada del Estado con la sociedad civil. La política estatal, modela e interactúa con la institucionalidad que asume el mercado.

Por lo que la informalidad es parte constituyente de la estructura productiva y territorial de la dinámica urbana capitalista, que pone de manifiesto el carácter multifacético y segmentado del mercado de trabajo y de tierra (que expresa la propia heterogeneidad del sistema social).

La informalidad urbana se explica: i) por condiciones macroeconómicas, como la falta de empleo, la baja salarial y el consecuente empobrecimiento de la población; y ii) las políticas del Estado y el funcionamiento de los mercados de tierra urbana y vivienda (Clichevsky, 2000, 2009).

Pero esta distinción analítica entre formalidad/ informalidad se hibrida y mixtura a nivel territorial, pues en él se despliegan acoplamientos e interrelaciones entre el sector informal y el formal de la economía. Por ejemplo, el sector formal provee capital e insumos al informal, mientras que los bienes y servicios producidos por éste suelen ser consumidos por asalariados formales (Rodríguez et al., 2015). Del mismo modo que hay agentes económicos informales que resuelven formalmente su relación con el mercado de tierra y vivienda y agentes inmobiliarios que desarrollan actividades informales para acceder al hábitat (Herzer et al., 2008b).
Cravino (2006) define el mercado inmobiliario informal como transacciones inmobiliarias mercantilizadas (es decir monetizadas) que no están ajustadas a las normas legales y urbanas vigentes, en donde sus agentes no adhieren a las reglas institucionales establecidas o bien no entran bajo su protección (Herzer et al., 2008a). Estos mercados no están liderados por agentes intermediarios típicos (como inmobiliarias) sino que trata de redes sociales en los barrios o, directamente, de transacción "cara a cara" entre los habitantes ${ }^{7}$.

La noción de informalidad se hace extensiva, entonces, para caracterizar no sólo las problemáticas asociadas con el mercado de trabajo, sino también, la forma en que se resuelve la relación de sectores flexibilizados con el mercado de tierra y vivienda y con el sistema de propiedad (Herzer et al., 2008b). Pues como se verá, en nuestros casos de estudio identificamos como demanda efectiva del alquiler informal en villas un espectro de trabajadores migrantes provenientes de países limítrofes, con bajos salarios, relaciones laborales precarizadas y - preferentemente - de género femenino con bajos ingresos.

\section{Aproximaciones metodológicas}

Este artículo se sustenta en un trabajo de campo, basado en la formulación de una encuesta no probabilística, establecida con criterios de muestreo teórico ${ }^{8}$, debido a las dificultades para establecer

\footnotetext{
${ }^{7}$ Existe escasa información sobre las características de los actores económicos productores de viviendas de alquiler informal en la CABA. A la modalidad ligada a la construcción de piezas por parte de familias con cierta capacidad para producir esta estrategia como complemento de sus ingresos, se suma — detectado cualitativamente- la emergencia en los últimos años - de completos edificios de inquilinato de piezas en villas, que responden a otro tipo de procesos del mercado informal y suponen otra capacidad de acumulación por parte de sus productores (Rodríguez et al., 2015).

${ }^{8}$ El muestreo teórico es el proceso de recolección de datos por la cual el analista selecciona, codifica y analiza su información y decide qué información escoger luego y dónde encontrarla para desarrollar su teoría tal como surge. Este proceso de recolección de información está controlado por la teoría emergente, sea ésta sustantiva o formal. Las decisiones iniciales para la recolección teórica de información están basadas sobre un tema general o área problemática (Glasser \& Strauss, 1969).
} 
el "universo" y a las condiciones de seguridad que inhabilitan entrevistar a los inquilinos en sus hogares.

El instrumento de recolección de datos, conformado por 120 preguntas (en su mayoría cerradas) estuvo dirigido exclusivamente a inquilinos residentes en las villas de la CABA, a los fines de recabar información acerca de las características físicas de las viviendas alquiladas, los arreglos económicos de alquiler, relevamiento de costos y una caracterización socio-económica del perfil del inquilino. El trabajo de campo se desarrolló entrelos meses de junio y noviembre de 2015 y se establecieron condiciones seguras de acceso a los inquilinos a través de redes organizativas e institucionales presentes en el territorio, considerando una pluralidad de expresiones de estas últimas como vías de mediación y generación de condiciones favorables para la realización de la encuesta.

El relevamiento se complementó con una estrategia cualitativa de realización de entrevistas semi-estructuradas a informantes claves de los barrios analizados que aportaron una contextualización de los ejes centrales de indagación de la encuesta. Los referentes barriales, al ser conocedores de la realidad de sus barrios, fueron consideradas personas idóneas para aportar a la investigación su conocimiento sobre la dinámica de funcionamiento del mercado del alquiler en sus barrios.

El criterio de selección de las villas - 31 y 31 bis, 21-24, Rodrigo Bueno, 20 y 3 - respondió a que se encuentran localizadas en las comunas 1, 4, y 8 donde se detectaron los mayores niveles de criticidad habitacional, en un marco donde la población — bajo estas modalidades de hábitat popular - ha ido en aumento.

\section{¿Quiénes son los que alquilan en las villas de la ciudad?}

[...] los inquilinos son los pobres de los pobres... Esos son los inquilinos... acceder a la tierra hoy en los barrios es imposible... (Entrevista 2, CABA, año 2015).

Las dinámicas de acceso a las villas y su consolidación variaron históricamente en función de la localización, crecimiento y densidad poblacional, así como del grado de tolerancia/intolerancia impulsado por el poder estatal. Aunque las villas en la CABA surgieron a partir de los años ' 30 , el mayor pico poblacional se evidenció en 1976, con 213.823 habitantes, cifra que se redujo sustantivamente a partir del plan de erradicación impulsado durante la última dictadura militar (Oszlak, 1991) '. Recién en los años ‘80, tras la recuperación democrática, las villas volvieron a repoblarse de manera constante hasta la actualidad generando cambios en las formas de acceso. Desde mediados de los '90, comenzó a manifestarse un proceso de densificación que, a causa del agotamiento de predios vacantes, tendió a dinamizar mecanismos de compra-venta de viviendas y alquiler de piezas dentro del mercado informal (Cravino, 2006, 2009).

En el marco del trabajo de campo, diversos entrevistados aseveraron que la dinámica de alquiler en villas recobró fuerza y mayor visibilidad en los años siguientes a la crisis de $2001^{10}$ en un contexto de reactivación económica. Una entrevistada de la villa 3 sostiene:

$Y$ hace años que venimos con el sistema de que te alquilan pedacitos [...] Este último tiempo... después de la crisis del 2001, se ve que en realidad la gente hace casas para alquilar. Ellos mismos viven en una pieza: el dueño de la casa vive abajo o hace un departamentito de $6 \times 5 \mathrm{mts}$., en alquiler... (Entrevista 1, CABA, año 2015).

Otro entrevistado de la villa 21-24 también comenta:

[...] uno de los cambios más significativos que tuvo el barrio, además de la explosión demográfica, tiene que ver con esto de los alquileres, que es uno de los cambios más notables que tuvo el barrio [...] Para mi empezó del 2005 para acá pero en los últimos años explotó... Se da conjuntamente con que los pocos lugares vacantes que había se tomaron y empieza la construcción para arriba, tanto para alquilar como para la familia... la inversión en ladrillo. Como toda la ciudad, con la recomposición económica, al tener un mango, compraban materiales, se ponía a hacer una loza, todos los que podían ahorraban en eso [...] en los últimos 6 -7 años fue impresionante,

\footnotetext{
${ }^{9}$ Hacia 1980 la población en villas alcanzaba sólo a 37.010 personas (CEyS, 2013).

${ }^{10}$ La crisis de 2001 en la Argentina fue una crisis política, económica, social e institucional como resultado de sucesivos ajustes económicos —ante el condicionamiento de los organismos externos-, aumento de la desigualdad social, desocupación y precarización laboral (Svampa, 2005).
} 
pasillos se transformaron enteros (Entrevista 3, CABA, año 2015).

Para los entrevistados señalar un "momento" de mayor auge de la dinámica del alquiler informal implica también identificar quiénes tienen acceso a ellas. La encuesta permitió evidenciar un número significativo de población de sexo femenino: el 67,1\% son mujeres, mientras que sólo el $32,9 \%$ son varones (ver Gráfico 1).

Casi el $42 \%$ de los inquilinos encuestados poseen entre $20-30$ años y el 31,4\% entre $31-40$, mientras que un 26,8\% representa una franja etaria de 41 años y más (ver Gráfico 2). Esto dio cuenta de una población predominantemente joven que, en la necesidad de lograr la independencia de los padres y/o forjar un hogar propio, inicia su trayectoria habitacional autónomamente en situación de alquiler informal.

Al reagrupar por población "argentina-extranjera" se observó, en el Gráfico 3, que casi el $67 \%$ de los inquilinos son migrantes de países limítrofes (provenientes de Bolivia -29,4\%—, Paraguay -22,4\%-, Perú $-13,2 \%$ - y en un $0,7 \%$ en cada caso son de Uruguay, Chile y Colombia) y el 33\% restante de los inquilinos villeros son de nacionalidad argentina.

Esta distribución por nacionalidad presenta variaciones según cada comuna, por ejemplo en la 4 , el $36,4 \%$ es paraguayo y el $13,1 \%$ es boliviano; los argentinos representan el 43,4\%. En la comuna 1, el $25 \%$ es peruano, siguiéndole la población boliviana y paraguaya (15,4\% y $14,4 \%$, respectivamente) y los argentinos un 41,3\%). Y por último, la comuna 8 concentra una mayor población boliviana (60\%), siguiendo los habitantes paraguayos (17\%) y argentinos (14\%).

La caracterización de "migrantes jóvenes" también se hace presente en algunos entrevistados:

\section{Esta población inquilina, ¿qué características} tiene? La mayoría migrante reciente, o parejas jovencitas que se van de sus casas y no tienen dónde comprar [...] ¿Qué pasa? Vos hiciste tu casita en el medio de un terreno y el baño afuera, a medida que fuiste creciendo y tus hijos crecieron les construiste su piecita al lado de tu casa, y cuando tuviste necesidad vendiste la mitad de tu terreno. Se construyó y empezaron a pegarse casas unas con otras. Vos a tus hijos en general no los dejas tirados, pero en el barrio la mayoría de las familias son en torno a la madre, que tiene hijos de distintos padres. La madre va quedando

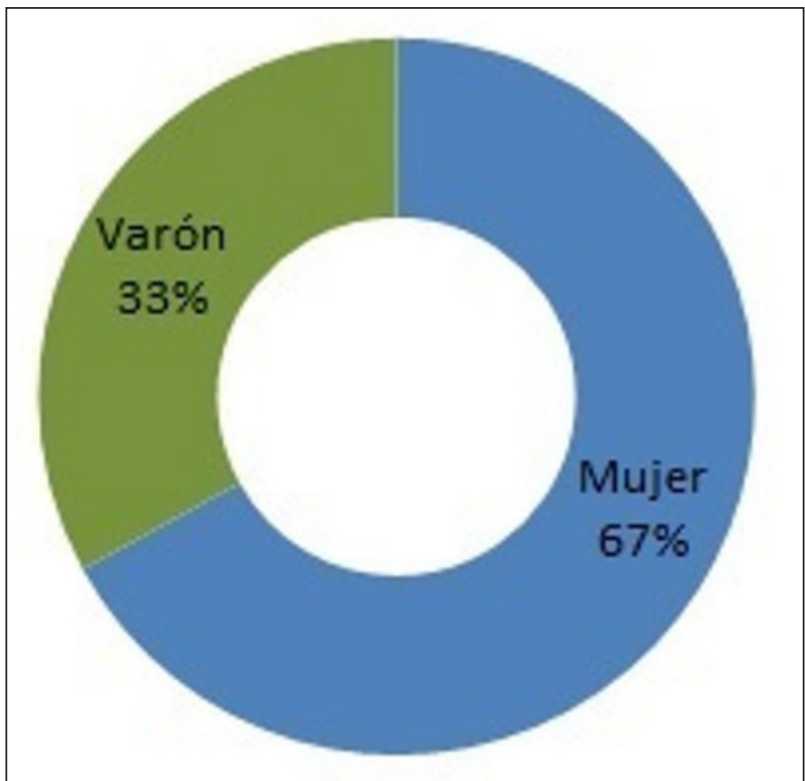

Gráfico 1 - Inquilinos en villa seleccionadas por sexo. Total. CABA-2015 Fuente: Elaboración propia.

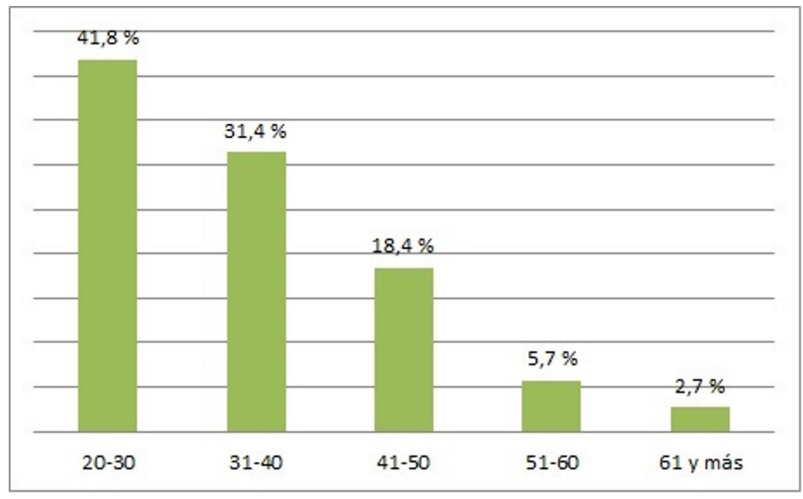

Gráfico 2 - Inquilinos en villa seleccionadas por edad. Total. CABA-2015 Fuente: Elaboración propia.

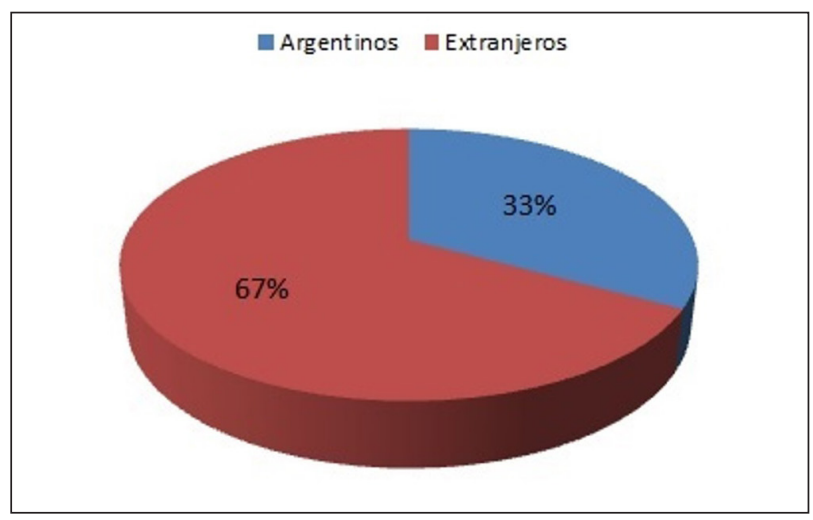

Gráfico 3 - Inquilinos argentinos y extranjeros en las villas seleccionadas. Total. CABA-2015

Fuente: Elaboración propia. 
en el mismo lugary los hijos van construyendo o creciendo o formando familia alrededor de ella. Puede ser la hija mujer o varón, que se hace lugar, se afinca arriba, construye. Ahora cuando eso se satura, o cuando se llevan mal con sus padres, ya no podes comprar en la villa. Antes tres mil pesitos, con tu laburo, entre los dos juntaban entre los dos y se iban. Compraban un mini terrenito y hacían una mini piecita, hoy no se compra más, no se vende más, y si se vende, ya te digo, cien mil mangos para arriba. Entonces qué pareja jovencita del barrio puede? Nadie, se va a alquilar (Entrevista 3, CABA, año 2015).

La mayoría son migrantes que vienen, son parejas muy jovencitas, que no tienen cómo acceder a la primera vivienda. Una pareja jovencita no tiene un laburo seguro. Algunos... la piba tiene dieciséis años, el pibe tiene diecisiete, dieciocho con un hijo y no puede vivir con los familiares, $y$ tampoco se le puede hacer ningún trámite porque es menor de edad. Es complicado. Y después, en una casa son quince, dieciséis personas en una casita, o sea que necesita salir, necesita alquilar (Entrevista 1, CABA, año 2015).

Abramo (2012) sostiene que el crecimiento del mercado de alquiler informal se asocia a la precarización del mercado de trabajo, pero también a una dinámica intergeneracional donde las familias jóvenes carecen de capacidad de ahorro, y de la obtención de un capital inicial para adquirir un lote o una casa, debiendo así alquilar.

Otro aspecto significativo identificado fue la condición de informalidad de los trabajadores inquilinos, - en tanto que si bien se observó cierto nivel de calificación en sus ocupaciones (muchos de ellos obreros metalúrgicos, textiles, de la construcción, trabajadores en áreas de servicios, seguridad, maestranza) - , un $69 \%$ manifestó no tener aportes jubilatorios y casi un $70 \%$ expresó no contar con cobertura de salud en sus trabajos. Esto demuestra que las familias inquilinas no sólo están atravesadas por la informalidad en materia habitacional, sino también por sus condiciones de trabajo, lo que convierte a esta problemática en algo estructural para la reproducción de sus vidas. Tal situación se agrava si tenemos en cuenta que dicha población encuestada también presentó un bajo nivel educativo: el 68,2\% del total (un total de 199 casos) no finalizó el secundario.
Asimismo (y como consecuencia), los ingresos promedio del hogar son muy bajos (ver Gráfico 4). Del total de la población encuestada, el 43,8\% de los inquilinos (133 casos) manifestó tener un ingreso mensual promedio del hogar de 375,1 a 750 dólares, mientras que el $41,8 \%$ (127 casos) se encuentra en una franja menor, de 135,5 a 375 dólares. Sólo en la comuna 4 la mitad de los inquilinos tuvo un ingreso promedio del hogar de 135,5 a 375 dólares, en la 1 y 8 la mayor proporción de habitantes se encuentran en la franja de los 135,5 a 375 dólares. No obstante, en la comuna 1 , un $12,5 \%$ de inquilinos contaba con ingresos de 750,1 a 1.875 dólares, a diferencia de la 8 y la 4 que sólo el 5\% (en cada caso) recibía mensualmente estos montos ${ }^{11}$.

Tomando en cuenta a Abramo (2012), uno de los motivos de la incapacidad de ahorro de las familias jóvenes para acceder a la compra de un lote está asociado a los altos precios de alquiler que deben afrontar con relación a sus ingresos. "]

El mercado informal de locación presenta una paradoja: al mantener precios relativos altos garantiza su demanda, cuando esta no es capaz de saltar hacia otro submercado informal de suelo, el mercado de loteo (Abramo, 2012, p. 53).

De este modo, el perfil del inquilino de las villas de la ciudad tiende a constituirse en núcleos familiares encabezados por mujeres jefas de familia, principalmente jóvenes, migrantes de países limítrofes (peruanas, paraguayas y bolivianas), con bajos niveles educativos, trabajadoras precarizadas y de muy bajos ingresos.

\section{¿Qué se alquila y cómo se alquila? Tipología de vivienda y arreglos económicos del alquiler}

A través de la encuesta realizada pudo observarse que el 81,3\% de la población encuestada reside en piezas, de la cual un $47,7 \%$ alquilaba una habitación en casa de familia y el $33,6 \%$ residía en edificios construidos específicamente para inquilinato (ver Gráfico 5). A nivel comunal el mayor porcentaje también se encontró en alquiler de piezas, con un $87 \%$ en la comuna 1 , un $84 \%$ en la 4 y un $73 \%$ en la 8 . Esta última duplicaba, con relación a las otras dos comunas, la cantidad de personas que alquilaban una casilla (6\%). El 90\%

\footnotetext{
${ }^{11}$ La conversión pesos argentinos-dólar oficial fue de 9,60 pesos ARG=1 USD, a noviembre de 2015.
} 


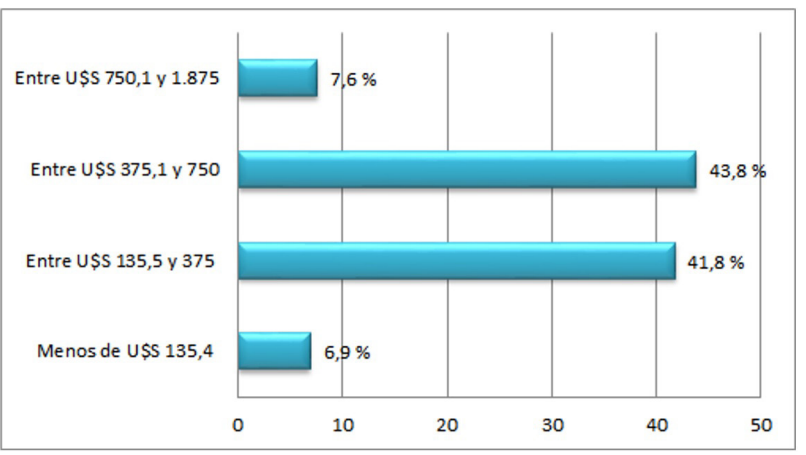

Gráfico 4 - Ingresos promedio hogar inquilinos (dólares) en villas seleccionadas. Total. CABA-2015

Fuente: Elaboración propia.

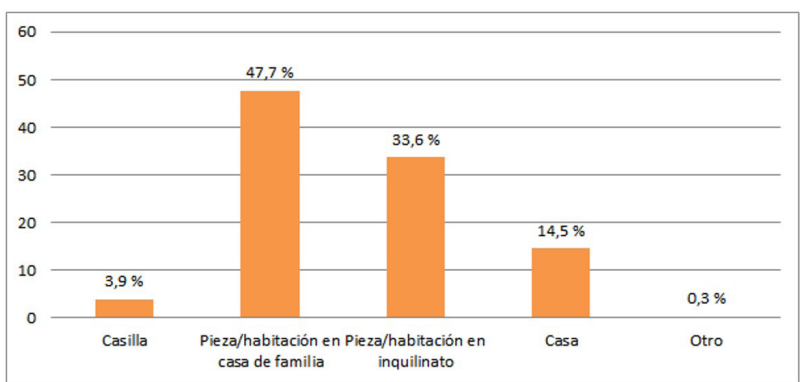

Gráfico 5 - Tipo de vivienda que se alquila en villas seleccionadas. Total. CABA-2015

Fuente: Elaboración propia.

se enteró del alquiler de la vivienda donde vivía por medio de un amigo/conocido o familiar que residía previamente en la villa.

La encuesta también reveló que la tipología de vivienda a alquilar varía conforme los niveles de ingreso. A mayor ingreso, mayor es la proporción de hogares que alquilan una pieza en inquilinato, en contraposición a los que tienen menores ingresos quienes acuden a alquilar un cuarto en casa de familia (ver Gráfico 6).

En cuanto a los equipamientos y servicios, aunque más del 72\% de los inquilinos relevados disponía de una cocina exclusiva ${ }^{12}$, sólo un $58 \%$ accedían a un baño exclusivo para su hogar. Casi el 75\% de la población total inquilina tenía instalación de agua en la cocina, el $93,4 \%$ utilizaba gas de garrafa para cocinar y el $99 \%$ contaba con electricidad en su habitación.

\footnotetext{
${ }^{12}$ En la mayoría de los casos, por "cocina exclusiva” se entiende al aparato cocina —anafe - en la propia habitación, no así una habitación aparte que cumple la función de cocina.
}

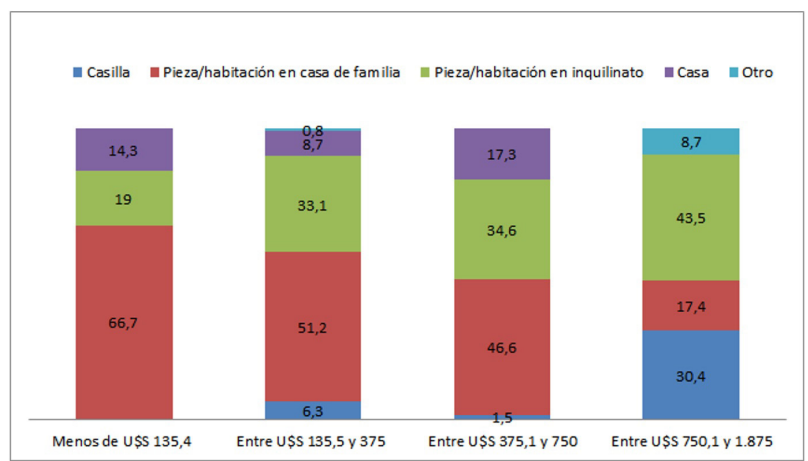

Gráfico 6 - Tipología de vivienda a alquilar según ingreso (dólares). Total. CABA-2015

Fuente: Elaboración propia.

Las precarias condiciones de las habitaciones es un aspecto presente en los relatos de los vecinos. Una habitante de la villa 3 expresaba: "La gente usa una garrafa... no tiene demasiada respiración [en la habitación], algunos tienen esa cocina eléctrica. Es muy peligroso." (Entrevista 1, CABA, año 2015).

Asimismo, una inquilina de Rodrigo Bueno comentaba:

[...] son dos piezas chicas. Uno es mi cuarto y el otro lo hice cocina y comedor y el baño es compartido. No hay cocinas afuera, no es como los hoteles. La cocina con horno está adentro de la habitación. Es chiquito, es incómodo, pero es lo único que puedo llegar a alquilar (Entrevista 4, CABA, año 2015).

A su vez, los valores de los alquileres están sujetos a variaciones y aumentos discrecionales. Por una sola pieza, el $37 \%$ del total de la población pagaba entre 52-104 dólares por mes, el 31,7\% entre 104,1-156 dólares y un 25,5\% entre 156,1 y más dólares ${ }^{13}$ (Ver Gráfico 7). El 58,6\% de los inquilinos manifestó tener que hacerlo entre los primeros 5 y 10 días del mes. En todos los casos el pago se realizaba en efectivo.

Además, el 47,7\% de la población se vio afectada por reactualizaciones anuales y un $24,9 \%$ a aumentos por períodos de tiempo menores a un año, mientras que sólo el $16,9 \%$ no había tenido incrementos por instalarse recientemente en el lugar. Los inquilinos están expuestos a residir de manera intermitente en el alquiler, trasladándose de una vivienda a otra, ante la falta de protección y resguardo. El 90\% de la

\footnotetext{
$\overline{13}$ La conversión pesos argentinos-dólar oficial fue de 9,60 pesos $\mathrm{ARG}=1 \mathrm{USD}$, a noviembre de 2015.
} 


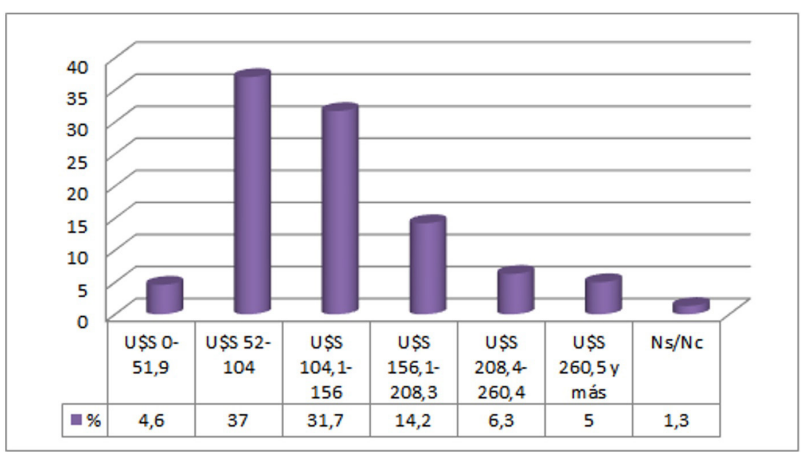

Gráfico 7 - Valores de alquiler (dólares) en villas seleccionadas. Total. CABA-2015

Fuente: Elaboración propia.

población relevada no recibió constancia de pago, a la vez que careció de contrato de alquiler.

Para el $86 \%$ de la población, la vivienda que alquilaba era su principal residencia. Entre las principales razones de por qué vivían allí, la mayoría de los inquilinos argumentaba: "no tener garantía para un alquiler formal" (28,3\%); "por trabajo" $(24,3 \%)$; "por familia" (21,7\%), "por no trabajar en blanco para un alquiler formal" $(9,2 \%)$.

La legitimidad de la transacción no descansa en un contrato ajustado al marco legal vigente sino en la ocupación de hecho del inmueble por parte del inquilino mediante un acuerdo de palabra, o a través de un acto donde auspicia como testigo el delegado de manzana (también referido reiteradamente en las encuestas y entrevistas realizadas) o incluso bajo algún tipo de "documento" escrito entre las partes. La presencia de un delegado que atestigüe no es más que el despliegue de otras formas de "garantía" para establecer confianza entre las partes, cuando la ley no se constituye bajo estas lógicas, es un mecanismo regulador de la relación contractual (Abramo, 2012).

Además, en este tipo de transacciones no intervienen agentes intermediarios típicos del mercado formal como las inmobiliarias, sino que operan - como modalidad de acceso al alquiler - las redes sociales ancladas en el territorio de los barrios o directamente los contactos cara a cara entre los habitantes de las distintas villas de la ciudad. De los encuestados, casi el 90,5\% se enteró de su vivienda ofrecida por un amigo o conocido o familiar mientras que los restantes se enteraron por algún cartelito pegado en la iglesia, algún comercio o en los pasillos del barrio. Los vínculos familiares y redes adquieren un papel fundamental en el acceso al alquiler, pues el "informante" - que en muchos casos también es conocido de los locadores - actúa como una "argamasa interpersonal" (Abramo, 2012, p. 43) en el establecimiento de la relación de confianza entre las partes.

\section{¿Cómo viven? Principales problemáticas: incertidumbre $y$ amenazas}

Una de las cuestiones que se hizo presente en los inquilinos fue la imposibilidad de obtener seguridad y estabilidad en el lugar donde se alquila, en gran parte por estar sujetos a condiciones que el propietario exige, sin ningún tipo de protección que regule y resguarde ese intercambio. Asimismo, la mayor preocupación residió en la inestabilidad laboral y la obtención de ingresos, pues la mayoría de los encuestados manifestaron que el mayor o menor riesgo a ser desalojados remite fundamentalmente a que se pague a término. Del 26,4\% de los encuestados que expresó sufrir un alto riesgo a ser desalojado, el 31,3\% fundamentó encontrarse en esta situación "por no cumplir con las condiciones exigidas de pago", siguiéndole en un 12,5\% "por tener niños/recibir visitas", "mal trato del propietario", y por "encontrarse la vivienda en mal estado/remodelación/ falta de comodidad" (respectivamente) y un 11,3\% "por estar próximo al riachuelo/camino de sirga"14 (ver Gráfico 8)

En este marco, la transitoriedad habitacional es un aspecto cotidiano en los inquilinos de villas. Si bien el $44,7 \%$ de los habitantes encuestados viven en la villa desde hace menos de 9 años, y un 36,5\% entre 10 años y más; la antigüedad en la vivienda que alquilan es menor, en tanto un $45,7 \%$ residía allí hace menos de 2 años, lo que da cuenta de un alto nivel de movilidad habitacional:

[...] el propietario te sube los montos, no hay forma de regularizarlo... Y que te pasa? Hoy te alquilo la habitación con las peores condiciones o te mudas a la otra habitación a dos cuadras. $Y$ así vas pululando. Yo conozco familias que alquilaron en cuatro o cinco lugares diferentes

\footnotetext{
${ }^{14}$ Este último argumento surgió entre los habitantes de la villa 21-24 afectados por la relocalización impulsada por la causa "Mendoza"; proceso judicial por el cual la Corte Suprema de Justicia obligó al Estado Nacional, los municipios provinciales y al Gobierno de la CABA a ejecutar el saneamiento de la cuenca Matanza-Riachuelo y relocalizar a la población de la villa 21-24 radicada a orillas del Riachuelo (Ver Fainstein, 2015).
} 


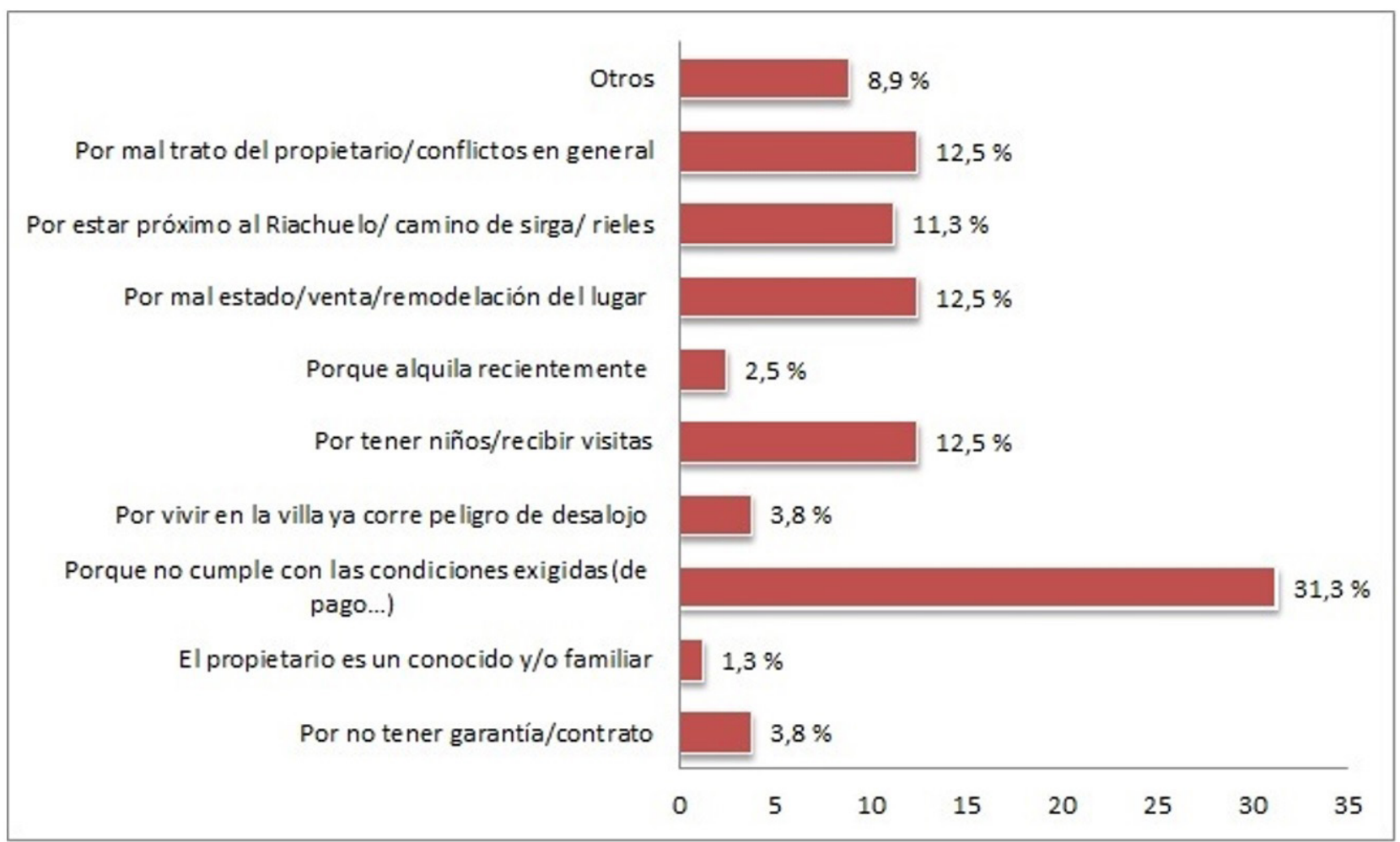

Gráfico 8 - Argumentos de los inquilinos sobre alto riesgo de desalojo en villas seleccionadas. Total. CABA-2015

Fuente: Elaboración propia.

de la villa. Y no hay contrato de dos años como tenemos todos en la ciudad formal [...] Yo tiendo a estimar que la gente cambia... cambia rápido... Rota mucho, rota mucho porque no hay ley... (Entrevista 2, CABA, año 2015).

Una vecina de la villa Rodrigo Bueno también comentaba:

Estoy ahora acá pero mis hijos me dicen que soy una hormiguita viajera porque fui cambiando. La primera vez vivía en la primera manzana que estuve como dos años. La casa era muy chica, y como estaba cerca del río mi nena se enfermaba, y me fui cambiando de inquilina a inquilina. Esta es la más tranquila de todos, no se mete en los problemas de los inquilinos, lo único que no quiere es que le rompan las cosas, que no se moleste a los inquilinos, pero más allá de eso no te hace problema... ¿Qué motivó que te vayas cambiando de habitación en habitación? Más que nada la incomodidad, son muy chicas las habitaciones. Si tenés una cama de dos plazas, ya no te queda espacio para moverte. En la anteúltima antes de venir acá, estuve dos años viviendo en la manzana
4, ahí sí alquile una habitación muy fea. Se me inundaba, se me llenaba de agua... (Entrevista 4, CABA, año 2015).

La falta de comodidad y espacio es otro de los temas que afectan día a día a estos habitantes, tanto para el propio desarrollo personal como para sus hijos. Evidentemente este "andar itinerante" tiene impactos en el desarrollo de la vida cotidiana de los inquilinos, pues ejerce fuertes condicionamientos sobre la posibilidad de construcción de una identidad en la villa, en las relaciones sociales y urbanas con el entorno, las posibilidades de organizar la vida cotidiana y de planificar en el mediano/largo plazo un proyecto de vida individual y/o colectivo.

En esta misma línea, los controles, el cumplimiento de horarios y las limitantes para vivir con chicos fueron aspectos que también potenciaron asperezas y conflictos.

\section{¿Cuáles son las principales problemáticas que tiene una persona que alquila?...}

Los chicos [...] Me dice: "Tenés que cuidar tus chicos, no pueden salir de tu casa", ese es el peor problema [...] Igual, para el mayor, mismo no hay 
libertad, porque no puede hacer nada, no puede tener invitados o tiene límites para entrar a tal hora. [...] Los inquilinos viven mucho encerrados, no tienen libertad, los chicos no tienen libertad para nada (Entrevista 5, CABA, año 2015).

Las restricciones que viven en su cotidianidad los inquilinos de villas dieron cuenta también de los niveles de abuso que existen por parte de los locadores debido a la falta de normativas que regulen dicha relación de informalidad.

En todos estos relatos también se hizo presente (por su acción o su omisión) el papel del Estado (Oszlak, 1991). La condición de informalidad, a diferencia de lo que sucede en el mercado formal, llevó a situaciones de indefensión para las familias dada la imposibilidad de contar con instrumentos de mediación y ejecuciones legales que los ampare.

Cómo viven y bajo qué condiciones residen los inquilinos en las villas no responde solamente a la relación que pueda establecerse entre el que ofrece y demanda una vivienda, sino también a la ausencia de políticas e intervenciones públicas que protejan y resguarden los derechos de los inquilinos.

Los entrevistados dieron cuenta de la total ausencia del Estado tanto en la regulación de esta relación, como también en la falta de estrategias y/o políticas que oferten mejoras en las condiciones de habitación de esta población:

¿Y hay algún espacio que defienda a los inquilinos ante esta situación? No, porque la mayoría son inquilinos [...] El gobierno no tiene un control sobre eso, no se hace un laburo, les chupa un huevo a todos... [...] ¿Y no hay ninguna defensoría? ¿La Justicia...? ¡No hay! ¿Quién te defiende? Si vos hacés la denuncia, te echan. Si ellos se llegan a enterar que vos dijiste que estuviste alquilando, fuiste, te echan (Entrevista 1, CABA, año 2015).

Los inquilinos constituyen el sector poblacional más afectado y vulnerado dentro de las villas de la ciudad, y que día a día se acrecienta ante la ausencia de políticas públicas que los cobije. Conocer quiénes son, cómo viven y cuáles son las características de alquiler adquiere gran relevancia no sólo para visibilizar una problemática poco abordada, sino también como puntapié para dar tratamiento a esta cuestión.

\section{Reflexiones finales}

Este artículo analizó las características que asume el mercado de alquiler informal en las villas de la Ciudad de Buenos Aires, prestando atención al perfil socio-económico de las familias inquilinas, las condiciones de habitabilidad de las piezas alquiladas y las características que asume la dinámica mercantil de este mercado informal. La información producida en el desarrollo de la investigación da cuenta que las familias que recurren a esta modalidad como estrategia casi excluyente de acceso a la ciudad, están excluidas del acceso a las condiciones del mercado de alquiler formal, del crédito y de las opciones de política pública habitacional vigentes.

El proceso de inquilinización que vive la ciudad no puede comprenderse por fuera de la reestructuración neoliberal de los países latinoamericanos en las últimas décadas, donde la informalidad habitacional, que es preexistente a ese ciclo, también asume características que la involucran dentro del proceso de mercantilización de bienes y servicios para los sectores populares. Pues en los últimos años, la expansión de la producción de la ciudad popular mostró la particularidad de articular la lógica "mercantil" de producción con la de la "necesidad", expresándose - a nivel territorial - mediante la expansión de un mercado con características informales. Amplios sectores reproducen sus condiciones de vida mediante una integración atravesada por la informalidad (la cual no es más que una forma distinta de resolución de la relación trabajo/capital, bajo la precarización y la flexibilización no sólo de las condiciones de trabajo sino también de las condiciones de acceso al hábitat). El mercado de alquiler formal e informal son dos caras de la misma moneda que lejos de ser categorías excluyentes se relacionan y retroalimentan en la dinámica de la ciudad capitalista de inserción periférica.

Ahora bien, la informalidad en el mercado de vivienda de villas asume ciertas particularidades. Su desarrollo implica la participación de determinados tipos de agentes mediante particulares tipos de transacciones. Los datos obtenidos a través del trabajo de campo realizado permitieron perfilar tendencias sobre algunas características que asume esta dinámica en las villas de la CABA.

Entre los resultados obtenidos, es llamativo que la mayoría de los inquilinos fueran jóvenes (entre 20 y 30 años), con permanencia extendida en la villa, pero que al independizarse de la familia 
y/o formar su propio hogar decidieron seguir allí autónomamente alquilando un lugar. También lo fue la gran proporción de mujeres bajo esta situación y la cantidad de migrantes. El 67\% de los inquilinos eran oriundos de Paraguay, Perú y Bolivia, lo que da cuenta de las dificultades que enfrentan estas poblaciones para localizarse en la ciudad consolidada (en un contexto donde en términos relativos los tres colectivos en conjunto constituyen apenas un 7,5\% del total de la población de la ciudad (CEyS, 2013).

Aunque presentaron un nivel educativo bajo, muchos se encontraban ocupados en tareas que requerían de cierto oficio y/o calificación, pero con niveles importantes de precariedad laboral y bajas remuneraciones, probablemente cualidades reforzadas por su condición mayoritaria de mujeres y migrantes.

Mujeres jóvenes, trabajadoras precarizadas y migrantes constituyen el perfil poblacional predominante de inquilinos en villas, en una sociedad que articula/ construye estos dispositivos habitacionales como forma de garantizar mínimamente la reproducción de esta fuerza de trabajo, bajo relaciones asimétricas y de desprotección que otorgan un condicionante más de vulnerabilidad al desarrollo de la vida cotidiana.

También se verificó que la tipología de vivienda a alquilar varía conforme al ingreso familiar, pues quienes poseen ingresos mayores alquilaron una pieza en inquilinatos, en contraposición a los hogares de menores ingresos quienes acudieron a casas de familia. En general, las habitaciones son muy reducidas, en donde las familias inquilinas deben compartir espacios comunes.

La mayoría de los inquilinos plantearon como principal preocupación la inestabilidad e incertidumbre habitacional, en gran medida sujetas a arbitrariedades por el pago del alquiler y los aumentos del mismo (que son establecidos de manera unilateral sin previo aviso). Esto es motivo de conflictos y tensiones con el dueño de la casa o encargado del inquilinato, así también en lo que refiere a cuestiones de convivencia y presencia de niños. Ante la ausencia de un contrato formal y normativa regulatoria, los habitantes se encuentran en una situación de alta vulnerabilidad y absoluta desprotección, mayor incluso que el resto de los habitantes que residen en las villas.

Esta estratificación interna del mercado informal de alquiler habla de un creciente proceso de heterogeneidad socioeconómica hacia el interior de las villas. Las distintas tipologías identificadas junto con las diversas formas de tenencia, incluido el caso de los edificios de inquilinato construidos exclusivamente para esa finalidad que presuponen un "propietario de lo construido" con significativa capacidad de inversión, evidencian un proceso marcado de segregación intra-barrial, que constituye un desafío para las políticas de regularización e integración en curso en esos barrios.

La precariedad y la ausencia de políticas reguladoras que garanticen mejores condiciones de habitabilidad son parte de una dinámica más amplia que excede la propia informalidad de las villas, producto de una desregulación presente en el mercado inmobiliario formal. Las políticas neoliberales refuerzan el proceso de mercantilización de bienes y servicios, convirtiendo a la ciudad en objeto y soporte de negocio en un doble sentido; tanto en el ámbito del mercado formal como también, en su extensión, en la propia informalidad donde resuelven sus vidas los sectores más vulnerados y excluidos en el proceso de acumulación capitalista.

\section{Referencias}

Abramo, P. (2003). A cidade da informalidade: o desafio das cidades latino-americanas. Rio de Janeiro: Ed. Sette Letras.

Abramo, P. (2012). La ciudad com-fusa: mercado y producción de la estructura urbana en las grandes metrópolis latinoamericanas. Revista EURE, 38, 35-69.

Bourdieu, P. (1997). Razones prácticas: sobre la teoría de la acción. Barcelona: Editorial Anagrama.

Carpio, J., \& Novacovsky, I. (1999). Introducción. In J. Carpio, E. Klein, \& I. Novacovsky (Eds.), Informalidad y exclusión social. Buenos Aires: SIEMPRO/OIT/Fondo de Cultura Económica de Argentina.

Clichevsky, N. (2000). Informalidady Segregación urbana en América Latina: una aproximación (Serie Medio Ambiente y Desarrollo, No. 28). Santiago: CEPAL.

Clichevsky, N. (2009). Algunas reflexiones sobre informalidad y regularización del suelo urbano. Bitácora Urbano Territorial, 1(14), 63-88.

Consejo Económico y Social de la Ciudad de Buenos Aires - CEyS. (2013). Diagnóstico socio-habitacional de la Ciudad de Buenos Aires. Buenos Aires: GCBA. Informe.

Consejo Económico y Social de la Ciudad de Buenos Aires — CEyS. (2015). La Ciudad de Buenos Aires inquilinizada: 
un análisis acerca del mercado formal e informal de alquiler como estrategia de acceso a la vivienda en la CABA. Buenos Aires: GCBA. Informe.

Cravino, M. C. (2006). Las villas de la ciudad: mercado e informalidad urbana. Los Polvorines: Instituto del Conurbano-Universidad Nacional de General Sarmiento.

Cravino, M. C. (2009). Relaciones entre el mercado inmobiliario y las redes sociales en asentamientos consolidados del Área Metropolitana de Buenos Aires. In P. Pirez (Ed.), Buenos Aires: la formación del presente editado. Quito: Olachi.

Fainstein, C. (2015). La relocalización de población del camino de sirga de la villa 21-24 ¿Erradicación o integración a la ciudad? Representaciones y repertorios de acción colectiva en torno al reasentamiento. In Actas de las VIII Jornadas de Jóvenes Investigadores. Buenos Aires: Instituto de Investigaciones Gino Germani, Universidad de Buenos Aires.

Glasser, B., \& Strauss, A. (1969). The discovery of grounded theory estrategies for qualitative research. New York: Aldine Publishing Company.

Harvey, D. (2007). Breve historia del Neoliberalismo. Madrid: Editorial Akal.

Harvey, D. (2010). The enigma of capital and the crisis of capitalism. Oxford: Oxford University Press.

Herzer, H., Di Virgilio, M., Lanzetta, M., Lucas, M., Redondo, A., \& Rodríguez, M. C. (2008a). El proceso de renovación urbana en La Boca: organizaciones barriales entre nuevos usos y viejos lugares. Revista HAOL, 16, 41-62.
Herzer, H., Di Virgilio, M., Rodríguez, M. C., \& Redondo, A. (2008b). ¿Informalidad o informalidades? Hábitat popular e informalidades urbanas en áreas urbanas consolidadas. Revista Pampa, 4(4), 85-112.

Instituto Nacional de Estadística y Censos - INDEC. (2010). Censos de población, hogares y viviendas 2010. Buenos Aires: Presidencia de la Nación.

Oszlak, O. (1991). Merecer la ciudad: los pobres y el derecho al espacio urbano. Buenos Aires: Estudios CEDES-Humanitas.

Portes, A. (1999). La economía informal y sus paradojas. In J. Carpio, E. Klein, \& I. Novacovsky (Eds.), Informalidad y exclusión social. Buenos Aires: SIEMPRO/OIT/Fondo de Cultura Económica de Argentina.

Rodríguez, M. C., Rodríguez, M. F., \& Zapata, M. C. (2015). La casa propia, un fenómeno en extinción: la "inquilinización" en la Ciudad de Buenos Aires. Cuadernos de Vivienda y Urbanismo, 8(15), 68-85. http://dx.doi.org/10.11144/ Javeriana.cvu8-15.cpfe.

Svampa, M. (2005) La sociedad excluyente: la Argentina bajo el signo del neoliberalismo. Buenos Aires. Ed. Taurus.

Theodore, N., Peck, J., \& Brenner, N. (2009). Urbanismo neoliberal: la ciudad y el imperio de los mercados. Revista Temas Sociales, 66, 1-11.

Recibido: Mayo 28, 2017

Aprobado: Oct. 31, 2017 